\title{
Behind the Scenes of Knowledge Sharing in a Japanese Bank
}

(Published in Human Resource Development International, 2001, 4: 465-485)

\begin{abstract}
This exploratory study discusses the way in which knowledge is shared in one of Japan's commercial banks. In particular, it highlights the social factors which act as catalysts in the knowledge sharing process, and considers the impact of HRM practices and the low level of interaction with outside institutions. It acknowledges the embeddedness of knowledge in social relations by adapting the community model of knowledge sharing. Contrary to the belief that traditional bureaucratic people management practices have a limited ability to support knowledge management, this study reveals an HRM system that is able to strike a balance between those practices and a 'paternalistic adhocracy' approach to sharing knowledge through collaborative task sharing, trust building and personal social networking.
\end{abstract}

\section{Introduction}

There is a growing body of literature (e.g. Grant, 1996; Drucker, 1993; Leonard-Barton, 1992; Nonaka and Takeuchi, 1995) addressing the issue of knowledge as the source of the firm's competitive advantage. In particular, in the emerging knowledge-based society, competitive organisations are increasingly seen as key generators and transformers of different kinds of knowledge (Tunzelmann, 1995). As a result, there has been a remarkable growth of 'knowledge work' (Starbuck, 1992; Alvesson, 1993) despite continuing efforts to reduce the size of the workforce in the manufacturing or goods production sectors.

In spite of the growing volume of research on knowledge management and its impact on competitiveness and innovation (e.g. Drucker, 1993) at the international level (Inkpen and Dinur, 1998; Mowery et al., 1996; Appleyard, 1996; Richter and Vettel, 1995), little is known about the conditions surrounding the management of knowledge in non-Western contexts, including Japan. A few previous studies (e.g. Fruin, 1997; Nonaka and Takeuchi, 1995) have attempted to identify the differences between the Japanese knowledge-creation model and the Western technology-based knowledge management model. For example, some of the practitioner-oriented literature on knowledge 
management (e.g. Finerty, 1997), referring mainly to Western experience, pays heed to tools and methodologies based on the technical dimension of managing knowledge. However, the importance of the social issues (e.g. Nonaka and Takeuchi, 1995) related to knowledge sharing, which forms the central focus of some of the knowledge-creation studies of Japanese organisations, has received less attention. Most existing studies are concerned with manufacturing industries (e.g. Fruin, 1997; Nonaka and Takeuchi, 1995), and, by contrast, the service industry, especially banking, has been neglected. Previous research carried out in the Japanese banking sector has tended to focus more on the role of banks in the Japanese economic system (e.g. Ito, 1995; Teranishi, 1982; Kazusaka, 1998), where the strength of the arguments rests on a macro-level analysis. Therefore, more knowledge-related studies of the micro-level processes of assimilation and learning are needed, as these processes are central to knowledge management (Scarbrough and Swan, 1999).

This paper, therefore, focuses on the micro-level processes and practices of the social dimension of knowledge management in a Japanese commercial bank. It provides an emphasis on understanding the interactions between knowledge sharing, long-term relationships, HRM practices, and the role of social networks. This discussion is limited to the internal dynamics of knowledge sharing at the bank. In spite of the recognised importance of the relationship between the elements conducive to knowledge sharing and the banking work processes, the discussion does not extend to detailing relationships with external stakeholders, such as the servicing of customers. A stakeholder analysis is beyond the purpose of this paper and would rather diverge from the objective of providing a rich detailed account of the internal activities of the bank and the way social networks, long-term relations and human resource practices relate to the outcome variable of the degree to which knowledge is internally shared.

This paper identifies three major processes and uses the Japanese case study to highlight the deficiencies of the 'new era' debate, which is "typified by flatter structures, 'debureaucratisation', decentralisation, networked forms of organisation and coordination through increasing use of information and communication technologies" (Swan, 1999:2). It also discusses the wider institutional context of the bank under study in relation to the historical development of the Japanese financial system. 


\section{Some Characteristics of Japanese Banks}

Financial systems vary from one country to another because they are embedded in the larger social context (e.g. Zysman, 1994; Whitley, 1997; Morgan and Sturdy, 2000). The Japanese post-war financial system, which is often labelled as a 'main-bank system' by scholars (e.g. Aoki and Patrick, 1994), was artificially designed within the larger institutional context in order to re-build the nation after defeat in the second world war and to prevent high unemployment. The financial sector was reformed to distribute capital to industries effectively and efficiently, thereby improving their productivity. As a result, banks achieved a high social reputation and played a major role in the Japanese society as key distributors of funds. In these circumstances, banks could have exercised their power to gain access to information concerning other organisations, for example, in relation to companies' business results, new contracts, alliance formations, innovations, and changes in management. However, they did not need to exercise this, because such information was provided to them in advance of any press release.

The role of technology as a source of competitive advantage in the banks was small. For instance, an association of large commercial banks was formed as soon as a new technology was introduced in the banking sector in the adoption of the given technology. In this way, banks shared the new technology and adopted a single infrastructure by consensus. As a result, all banks could provide new products at the same time by following the same scheme. The advantage of this system was the opportunity it provided to avoid costly trial-and-error experimentation, while the disadvantage was the delay in providing new and, at times, more costly services to customers. The introduction of the direct debit card in 1999 exemplifies this delay.

In actual practice, individual banks had few alternatives for generating new business activities and launching new financial products. They were strictly regulated and fully protected by the government. This system was known as 'Goso-Sendan Hoshiki' or the 'convoy system' (e.g. Enkyo, 1993; Horiuchi, 1998). It was more amenable to generalist rather than specialist knowledge, because general 'firm-specific' knowledge was considered as more important than 'product- and function-specific' knowledge. The system was also conducive to personal social networks as a means of sharing knowledge. 


\section{The Community Model}

In the case presented here, knowledge is defined as the explicit job-related information and implicit skills and experiences necessary to carry out tasks. In other words, knowledge is perceived as more than simply information, and is seen as embedded in the skills and experiences of employees and constructed through social relationships and interactions (Nonaka and Takeuchi, 1995). Consequently, an organisation faces vulnerability upon the loss of that knowledge which occurs when employees choose to leave the company. The case study presented in this paper shows how knowledge ingrained in the dynamics of human relationships is often more fundamental than the use of IT in the practices of a Japanese bank. Long-term employment relationships, HRM practices and social networks play a crucial role in the internal sharing of knowledge. This case, as far as the Japanese context is concerned, also serves to downplay the argument that traditional bureaucratic people management practices limit the degree to which knowledge is shared (e.g. Swan, 1999:11). The paper adopts the community model (Swan, 1999:11), as seen in Table 1, in order to acknowledge the embeddedness of knowledge in social networks including occupational groups and teams. This model highlights the importance of long-term employment relationships, shared understandings, and attitudes to knowledge formation and sharing within organisations. Although the model is developed in the light of knowledge management, it also applies to the knowledge sharing process. 
- Knowledge is socially constructed and based on experience

- Knowledge is transferred through participation in social networks including occupational groups and teams

- Gains from knowledge management include greater awareness of internal and external ${ }^{1}$ sources of knowledge

- The primary function of knowledge management is to encourage knowledgesharing amongst and between groups and individuals

- The dominant metaphor is the human community

- The critical success factor is trust

Table 1: The Community Model of Knowledge Sharing

Source: Adapted from Swan (1999:11)

In the first section, the research site and methods are described. This is followed, secondly, by a discussion of the background and the details of the case study, which outline the factors that are critical in the bank's ability to collaborate and share knowledge. The final section presents the conclusions.

\section{Research Site and Methods}

This paper is based on an ethnographic study of the knowledge sharing features of a Japanese bank, and focuses on the role of the key organisational processes that shape the inter-relationships between these features. A qualitative, retrospective approach is adopted. The research is based on a single case study, employing unstructured interviews, and the primary researcher's own on-site observations through her employment at the bank between September 1993 and July 1997. Given the practical limitations, the researcher has attempted the gain a multiplicity of views from various members of the same group, that is the middle management level in the bank.

\footnotetext{
${ }^{1}$ The case highlights that awareness of the external sources of knowledge sharing is applicable only to the specialists in the given bank.
} 
The main fieldwork was conducted at the bank's headquarters via participant observation during the primary researcher's employment period. Given Japanese financial institutions' strong emphasis on the importance of confidentiality, the researcher was obliged to immerse herself in the social, political and technical aspects of the bank's operations through an employment contract. The field researcher attempted to become part of the setting being studied, with the goal of describing the setting in as much detail as possible. The objective was achieved through direct involvement with the subjects under study and personal experience of the daily life in the setting (Neuman, 1991). Participant observation allowed for a better understanding of the dynamic interplay of the strategic elements that played a big role in the knowledge sharing process. A major advantage of this kind of observation is that it permits a "here-and-now, in-depth experience" (Garvin, 1993, Lincoln and Guba, 1985). Observations of individuals at work were used to verify or elaborate on the interview data.

The research is not concerned with identifying discrete taxonomies of knowledge-sharing systems, but with examining the social relations and processes surrounding knowledge sharing. Under these circumstances, interviews would only provide an incomplete account of those relations and processes, and would not enable an in-depth understanding of the organisational culture and its relation to knowledge sharing in the selected bank. By contrast, an ethnographic research methodology makes it possible for an insider to capture, understand and analyse social relations, social processes and methods of management support through retrospective research (Hammersley and Atkinson, 1995). For example, it would not have been possible for an outsider to understand effectively the nature of informal groups and personal social networks through discussions with managers and employees over a short period of time (e.g. Mintzberg, 1973). In the given case, it was necessary to learn the informal rules that were being followed and the way these were interpreted. A process-based account enabled the researcher to understand the situational logic and the impact of conditions in the bank directly related to knowledge sharing.

Unstructured interviews with the management were conducted between March and August 2000 to enrich and verify the ethnographic data. Interviews were unstructured in order to provide greater in-depth understanding of the key factors that shape the process 
of interacting socially and sharing knowledge. According to Fontana and Frey (1998:56), unstructured interviewing has a crucial role to play in fieldwork. It encourages interviewees to express themselves in their own terminology, and their experiences are not restricted to pre-defined questions. The range of interviewees covered the areas of investment management, private banking and research, and represented the middle management level in the bank. Interviews were tailored to each particular group of informants and concentrated on their perceptions of what happened and why, on how decisions were influenced and made, and why conflicts emerged and how they could be resolved. Six interviews were conducted to complement on-site observation. Interviewees consisted of male middle-level managers in their mid-30s in various departments of the bank. The questions were open-ended and each lasted from one to one and a half hours. The discussions focused on the details of knowledge sharing process in the bank, each actor's role, experience and aspirations, and the perceptions of other involved in the same process. Questions were also asked about the influence of various contextual factors on the process of knowledge sharing activities.

To achieve high-quality analysis, collected data were coded and analysed. During the coding process, interview transcripts were analysed through the categorisation of emergent concepts and ideas and constant comparison of these concepts (Glaser and Strauss, 1967) in order to identify common themes. Interview notes were organised across informants according to key components of the interview guide (where components were based on social network characteristics). The data collected were initially broken down by asking simple questions focusing on what, where, how, when, how much etc. Some of the emerging themes in the process included the emphasis on social networks, HRM practices, trust, long-term relationships and group membership.

These preliminary themes and topics were then analysed and aggregated to arrive at a set of topics that were commonly recurring. A number of themes, such as gender related differences in perceptions emerged in the early stage of data analysis, when the initial analysis revealed them to be of indirect relation to the theoretical model. All data were then re-studied and re-categorised in terms of a new set of common themes. Interpretation of empirical data was furthered through discussions with other members of the research group. This was necessary for the validation of data interpretation (Besser, 1996:31). 
Such an iterative analysis of data and themes, as suggested by Orlikowski et al (1996), allowed for the emergence of a conceptual framework that reflected the grounded experiences and interpretations of the actors in their contexts, whilst also providing an analytic framework for other contexts.

\section{The Case Study: Michiko Bank ${ }^{2}$}

Michiko Bank was established in the 1850s, during the Japanese industrialisation period of the Meiji era. It is a core member of one of the Keiretsu groups. This group provides not only a long-term customer-supplier relationship but also financial resources to Michiko. Michiko provides 40 per cent of its loans to the Keiretsu group and is also engaged in a cross-shareholding agreement within the group. This is in line with the general trend described by Gerlach (1992:18): “when we look only at the top-ten shareholders, the share of total stocks controlled by companies in the same group rises to over 25 per cent in all major inter-market Keiretsu and over 50 per cent in the older, Zaibatsu-based groups" (Italics by author).

Michiko has approximately 10,000 employees. Its headquarters is located in Tokyo, and it has several branches throughout Japan and abroad. It is one of the top commercial banks in Japan and enjoys a high social reputation. It maintains a large deposit base from both individuals and companies in Japan. As a traditional, long-established bank, Michiko's organisational structure is rather concretised, that is rigid, with little room for instantaneous and rapid change. It is hierarchical and highly centralised. Michiko's headquarters exercises close control over its domestic branches. It is perceived as the most significant profit centre responsible for generating revenues for the whole organisation. The profit-making ability of the branches is rather sidelined. The headquarters also has close ties with external authorities, such as the Ministry of Finance (MOF) and the Bank of Japan (BOJ).

In spite of the rigid organisational structure of Michiko, there are a number of social mechanisms - long-term employment relationship, HRM practices, and social networks -

\footnotetext{
${ }^{2}$ Michiko is a pseudonym; all names in the article have been changed to ensure anonymity.
} 
that support knowledge sharing within the organisation. These will now be discussed in turn.

\section{An Emphasis on Long-term Employment Relationships}

Lifetime employment and harmonious intra-group relations are seen as two crucial contributors to knowledge sharing.

\section{$\underline{\text { Lifetime Employment }}$}

Lifetime employment is a common practice for core employees ${ }^{3}$ in large Japanese banks. As Iwata (1982:51) points out;

when we put together the fact that Japanese-style management has a dual structure consisting of the core and periphery, that at the root of this structure is the basic framework built on the performance of relations...we must recognise the lifetime employment system as being one of the essential elements creating the unique features of Japanese-style management.

Male employees, who joined Michiko straight after graduation in April each year, are identified as 'core employees'. The implicit rule is that only this population has the opportunity to reach a senior management position in the bank. From Michiko's viewpoint, this group of male employees constitutes the most important human resource for the bank. Hence, it is crucial for Michiko to guarantee its employees a salary level, position, and work environment conducive to high motivation and job-satisfaction.

From a wider institutional perspective, lifetime employment is embedded in the Japanese social and legal system. For example, if an employee at Michiko is to change his company, he would face the possibility of a serious financial loss in terms of the company-based pension and large retirement payment, which are both positively correlated with the number of years one spends in the company. Iwata (1982:67) points out that,

The members that make up the core of an organisation are generally regarded as "colleagues" that work together, under permanent relations, until retirement age, to attain the organisational objectives... Throughout 
this process, he [that is the core member] forms a network of friendly relations, in various forms, with many other members of the same organisation, builds up his information network, and accumulates knowledge on in-house situations and history.

The lifetime employment practice at Michiko provides a framework for sharing knowledge in two ways. First, the employees have stable positions, so they have the opportunity to gradually get to know each other over a long period of time. There is the implicit recognition of a working relationship of about 20 years among the core employees. Secondly, Michiko employees are identified as belonging to the same bank, and are, in turn, expected to display the same attitude and conduct towards external institutions. Consequently, both job security and identification with the organisation create an environment in which knowledge sharing becomes easier.

Life-time commitment to the bank has the additional benefit of allowing its members to share the same experiences repeatedly. Therefore, it becomes easier to diffuse tacit knowledge ingrained in these 'shared' experiences within a casual and family-like atmosphere. For instance, most members at Michiko are familiar with the historical events that are experienced by their departments. Tacit knowledge and implicit rules of conduct, which cannot be captured in documentary form in a report or a manual, are created in communities of practice, based on fluid job description, in-house training, and job rotation, where groups handle specific problems. Communication and personal relations serve as a means of accessing 'collective memories' (Yoshida, 1996) in different departments.

\section{Group Membership}

At Michiko, it is important to maintain harmonious relationships in the group to which one belongs. For instance, each department at Michiko holds social events, such as welcome parties for newcomers or contests for existing employees and their families, in order to strengthen group bonding among its members. Members are expected to be present at these events. By the same token, they are required to abide strictly to the official working hours of 9 am to $5 \mathrm{pm}$, and are also encouraged to stay beyond $5 \mathrm{pm}$ to

\footnotetext{
${ }^{3}$ At the time the study was conducted, core employees were composed mainly of male entrants.
} 
display their sense of belonging to the bank and sensitivity to harmonious relationships. The bank sees it as necessary that "a conformist mentality is able to suppress one's selfassertion" (Iwata, 1982:54). Sustained harmony is considered as one of the most important requirements in order for the maximisation of organisational outcomes. If an employee has a different opinion from the rest, it is better for him to remain silent. This is because arguing is considered as a personal attack on the bank. Emotional harmony between members is preferred to logic, so much so that the members become preoccupied with the 'small (personal) matters', such as one's marital status, in the bank. The System Unit Manager (10 August 2000) claims that "members are blind to what goes on outside the bank. Rather, small matters in the bank are very important for them".

Michiko's emphasis on group harmony differs from the values on which Western business-related activities are based. According to Hodgetts and Luthans (1997:67), Japanese values, such as belonging, group harmony and collectivism, are more important than the values of freedom, independence and self-reliance, which are regarded highly in Western countries, such as the United States. However, with its growing body of specialists, Michiko finds it difficult to nurture emotional harmony within this group. For example, attaining emotional harmony among portfolio managers, working in the asset management department, is found to be difficult. Specialists in the bank are driven by a strong desire for personal achievement, and this reduces their need for strong group membership in the bank. Specialists' portable knowledge (Shimizu, 1999:231) allows for mobility and reduces the sense of strong affiliation with the bank among the specialists. Consequently, they are less inclined to share their knowledge with other groups in the bank. This clearly contradicts the 'human community' component of Swan's (1999) community model.

Michiko's norms of group membership, which are only applicable to the core members, shape its employees behaviour and create homogeneity in the bank, thereby facilitating knowledge sharing. This is exemplified by the Trading Unit Manager's (28 July 2000) claim that "we take it for granted that we are members of Michiko. We are not even aware that we are employed at the bank". It seems that it is "relatively easy to share knowledge across a group that is homogenous" (Swan, 1999:11). Identification with the group is also felt at a company level and can be observed in employees' transactions with 
outside institutions. Employees label their relationship with the bank as 'uchi no ginko' ('my bank'), similar to 'uchi' ('my family').

On the other hand, one of the "vital ingredients for the success of knowledge management is the interrelationship with HRM" (Pan, 1999:80). The sub-sections that follow therefore detail the impact of job-rotation, in-house training, internal promotion and fluid job description on knowledge sharing in Michiko Bank.

\section{Human Resources Management (HRM) Practices}

$\underline{\text { Job Rotation }}$

Job rotation is a common training practice at Michiko. All new recruits start their career in one of the domestic retail branches as a cashier, deposit operator, loan section clerk, or customer section clerk. They then rotate across divisions within the bank every three to five years by order of the HRM Department. Once the order is given, workers cannot refuse to shift jobs. The research findings show that job rotation provides the opportunity for employees to work with others across various functions in the bank and keep the information network alive. Job rotation of members who have had previous working relationship in the same department allows strong networks of information to develop. One of the managers in the Asset Management Unit claims that "it is amazing how information is spread within the bank. People are always talking on the phone" (14 August 2000). Job rotation seems to help in building an atmosphere of familiarity and common membership among employees. In other words, "job rotation increases the feelings of camaraderie with other team members" (Besser, 1996:74).

In addition, job rotation imparts to employees a general perspective about the bank's activities as a whole. A Michiko employee can carry out the tasks assigned by a particular department even after his transfer out of that department. This allows for flexibility in the bank. There is a spontaneous positive attitude to sharing information on the basis of an expectation that the act can be reciprocated in the future, for every employee has the chance to become a potential colleague through the job rotation system. For instance, "in the bank's appraisal system, boss' evaluation of members is everything. We try to know other peoples' formal and informal position in the bank" (A Manager in the Asset Management Unit, 14 August 2000). This differs from sharing knowledge on a shortterm, cross-functional, cross-disciplinary project basis. In the case of Michiko Bank, the 
sense of ownership and departmental expectations of task accomplishment are found to be higher within a job rotation system, where ongoing interactions are allowed a longer time to develop and contribute to knowledge sharing.

\section{$\underline{\text { Standardised In-house Training }}$}

In addition to job rotation, new starters at Michiko are subjected to two to three years of training in order to become generalists:

The opportunity through which we get to know each other is, firstly, the collective in-house training upon joining the bank, secondly, job rotation. Knowing each other through collaborative work has less meaning. (Bond Unit Manager, 23 March 2000)

During the training period, new starters at Michiko are supervised by senior tutors who have joined the bank a few years before them, and their own bosses. This gives them the opportunity to acquire general knowledge about Michiko's banking activities and organisational culture by learning on-the-job. Senior tutors themselves are trained in accordance with the bank's norms of conduct in external and internal interactions. The bank is seen as having its distinct culture. "This bank has its own way, everything new is rejected because they have no history" (Trading Unit Manager, 28 July 2000). This includes knowing who is important in the bank, and how to ask questions and negotiate for certain conditions.

Other structured compulsory programmes include training in basic property law, accounting, and finance for young workers, and management skills and qualification lectures for managers. All trainees are examined at the end of the programme. One of the reasons for such a standardised and rigid in-house training programme is that "there are few independent institutions of management education available in Japan" (Sasaki, 1990: 43). Standardisation of training enables fair treatment of employees. However, this fairness is not expressed in opportunities, for instance for promotion, but rather in the outcomes reached in terms of goal achievement. This helps to sustain employee motivation. In this context, the HRM Department's main concern rests on upgrading the 
skill levels of the low-performing groups, rather than on prioritising high-performing groups.

In-house training at Michiko creates an informal atmosphere conducive to sharing knowledge. The merits of this practice can be observed in the provision of updated information concerning other members' tasks, the acquisition of 'common sense' conduct in 'Michiko society', the minimisation of inter-departmental biases in the bank, and the acquisition of job-related information.

\section{Internal Promotion}

There are two significant motivating factors for the majority of Michiko employees: job security and the opportunity of promotion to the highest possible rung in the hierarchical ladder. Supply of information partly depends on one's potential to be a powerholder. "The key point in whether one will supply information or not depends on whether the counterpart has power, or the potential to be promoted in the bank" (System Unit Manager, 10 August 2000).

Michiko members' salary differences are relatively small, hence salary level itself does not serve as a significant motivator. On the other hand, an individual's position is regarded as very important both within and outside the bank. According to Iwata (1982:62);

It is correct to say that Japanese people's awareness of status tends to consist of two things; an awareness of the status of the group, and an awareness of the individual status relations within the group...Externally, since the Japanese people position and evaluate each other on the basis of the group they are affiliated with, they tend to become extremely sensitive about the social prestige of the group.

Given the sensitivity towards social prestige and the associated job satisfaction and salary implications, internal competition between core employees at Michiko is intense. This is accentuated by the selection of the branch managers, board members, and the CEO from among the core workers. 
Although the HRM Department emphasises fair treatment of core employees to stifle high competition, the availability of the CEO position to approximately 1,000 male candidates does not alleviate the tension. Michiko tends to create internal positions for core workers, such as those of assistant manager, deputy manager, and sub-manager, around a single managerial position in order to reduce this tension. Ironically, this competition increases the frequency of unofficial and informal information transfer concerning events related to employees' promotional opportunities, and the power relations in the bank. As a manager in the Asset Management Unit (14 August 2000) suggests, "I was wondering if it was worth knowing who moved where, who got promoted. All my colleagues are constantly talking about these things". The internal promotion system enables employees to play their cards as effectively as possible despite efforts by the bank to reduce competition through managerial redundancies.

\section{Fluid Job Descriptions}

Iwata (1982:52) notes that "unlike the American-style companies where the institutional structure is quite logically arranged on the basis of clearly defined individual tasks, work is allocated to sections and divisions in Japanese companies". Hence, job descriptions are fluid at Michiko. "Departments do not have fixed roles in the bank. Hence they can try to load difficult tasks on to other departments" (System Unit Manager, 10 August 2000). Basically, various tasks in a given department can be assigned to any departmental member. Therefore, the circulation of information concerning the nature, due date and the resource availability of the task to be completed is of fundamental importance in the bank. Each member's ability, knowledge, position, network of relationships, and even holiday plans also needs to be assessed, for they are seen as having repercussions for other departmental members. For example, if a member of a particular department is on a holiday or is in hospital, his job will be taken over by another colleague in the least disruptive manner. Fluid job descriptions encourage strong co-operation among members within the same department both at a functional and an emotional level. This contributes to the team spirit in the bank, for members can share in an individual's achievement and the associated job satisfaction. This is seen as central to the efficient running of operations. 
It must be noted, however, that the fluidity of job descriptions does not apply to the minority group of specialists in practice. Although, officially, they are seen as having fluid, blurred job boundaries, their work-in-practice as compared to that of generalists, has clear boundaries and is more rigid and task-oriented. Other departments are not aware of the implicit contract that the body of specialists has with senior management. Hence, generalists follow the implicit rules of directing requests outside a given area of specialism, to the specialist members. Such requests are not in line with the expectations of specialists. This creates divergence of expectations, and is addressed by introducing a dual career system in the Japanese bank. A dual career system serves as a means of avoiding conflict between the specialists and the generalists. The knowledge sharing process at Michiko is also facilitated by social networking efforts and the formation of trust.

\section{The Role of Social Networks}

Vertical relationships

The formal authority relations at Michiko, encompassing the flow of orders from managers to lower-level employees, resemble the rigid, vertical structure presented in Figure 1.

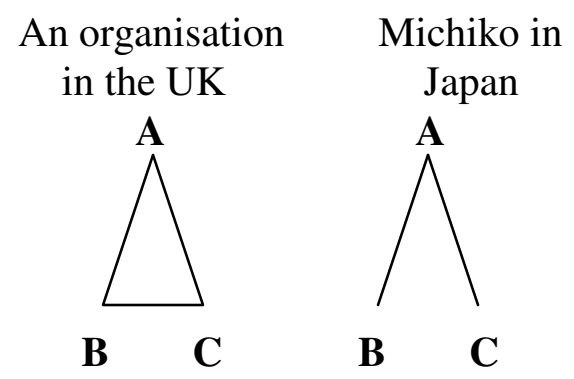

Figure 1: The manager-worker relationship Source: Nakane (1970:117)

In Figure 1, $\mathrm{A}$ is a manager, and $\mathrm{B}$ and $\mathrm{C}$ are office workers. If $\mathrm{B}$ were to request $\mathrm{C}$ 's help in the UK, B would go to ask C directly. However, in line with Nakane's (1970) argument, that the official organisational structure in many Japanese firms is based on vertical relations between members, Michiko does not support such a horizontal relationship. At Michiko, if B were to request C's co-operation, B would need to ask manager A's permission, who would in turn direct $\mathrm{C}$ to offer assistance to $\mathrm{B}$. 
The official boundary between departments in Michiko bank is strong, partly because, all members are assigned departmental rather than individual tasks. This is to deter members from displaying radical behaviour that deviates from the expected code of conduct. However, the inter-departmental wall is not high enough to inhibit knowledge sharing across departments.

Although, in theory, a strong and rigid hierarchy coupled with strong boundaries between departments is an intervening factor for knowledge sharing, in practice, as observed at Michiko, the official structure promotes the transfer of unofficial information. For instance, a member needs to be familiar with other departmental members' abilities or tacit knowledge, and the circumstances surrounding his department, before he can approach him for help, in order to achieve time efficiency. He needs to be well informed of the task requirements and the nature of the desired co-operation before he can request the dedication of another departmental member's time. Requests for assistance, thus, have implications on overall departmental outcomes.

\section{Social Networking}

Given the lifetime employment practice at Michiko, members prefer not to be on bad terms with others in the bank. Each member has the potential of being another member's colleague or boss as a result of job rotation. Michiko employs a strategy based on a combination of high internal competition and 'avoidance of animosity' (Shimizu, 1999). Although this seems paradoxical, employees are familiar with the course of action to take. They try to gain central positions in the network of knowledge sharing by creating dependency relations. In fact, unfamiliarity with colleagues in other departments is seen as existing outside the known codes of conduct. "I had a funny experience once. I asked my boss to forward an inquiry about a matter to another department. He answered that he did not know the person in charge. (A Manager in the Asset Management Unit, 14 August 2000). The most important tool available to the employees is the building-up of an effective personal social network.

At the level of a horizontal network, it is important for the same-year entrants to have graduated from the same university. For example, "the strongest university party at the bank seems to be that of the University of Hitotsubashi. They have a regular gathering 
once a month." (Bond Unit Manager, 25 March 2000). The new entrants establish interdivisional informal groups, based, for instance, on graduation from the same school, residence in the same bank property, starting their careers in the same branch, or the move for residence in the same prefecture. For example, if a core member happens to be in a division, which does not fit in with his background, then he can make unofficial complaints via this internal social network. These complaints can then be carried to higher management through the vertical relations of those colleagues who are also enrolled in the same informal group. Consequently, opportunities for informal communication and socialisation during after-work hours are crucial in establishing a social network. A contrasting example to the social relationship efforts of the core members is the practices of the small group of specialists at Michiko. Specialists tend to create their networks outside the bank. They constitute the group that is aware of the external sources of knowledge (see Swan's 1999 community model). Their exchange of information with outside bodies is resented by the generalist insiders. The networking efforts of the specialists with external actors are regarded by the generalists as a betrayal to the company, for in their perception the 'secrets' of the bank are being disclosed to competitors.

\section{$\underline{\text { Trust }}$}

In line with the generally shared definition of trust in Japan (see the discussion of 'goodwill trust' in Sako, 1992), Michiko employees build trust, involving psychologically deeper ties than those based on mere cost-benefit calculations, through inter-personal relations at and outside work. A manager in the Asset Management Unit (14 August 2000) defines it as “we have very little sense of trust that is related to one's organisational position. It could be said that all trust is based on personal relations in the bank". This is contrary to the German context, for example, where trust is based on a person's professionalism, expertise, and skill rather than personality traits (Lane, 1997). Emotional bonding among the employees within a department at Michiko is strong, given the emphasis placed on open commitment, so that members "entertain shared principles of fairness and convergent mutual expectations about informal obligations" (Sako, 1992:39). The nature of this trust is more contextual, and verifiable in particularistic settings. It is related to the company to which individuals belong. In the case of Michiko, bankers trust each other because they are working for the same bank. Therefore, it becomes difficult to 
sustain trust when one's membership comes to an end. This is exemplified by the core employees' unwillingness to take early retirements. Strong personal relations within the bank draw rigid boundaries between Michiko and external institutions. Moreover, interdepartmental boundaries take on a different meaning when the overall bank objectives are considered. In other words, those boundaries are weaker than the protective 'hard shell' surrounding the whole organisation. Sako (1992:48) argues that,

Particularistic open commitment created by 'goodwill trust' is a powerful springboard from which to unleash effort but at the same time is prone to closing off access by outsiders to personal networks.

Consequently, the creation of constant and reliable expectations of flexibility runs the danger of creating excessive rigidity.

Trust building at Michiko requires constant exchange of knowledge and information through frequent and intense communication and the giving of mutual assurances. According to the System Unit Manager (22 March 2000), "it is important to build trust if one wants to do well in the bank. But, trust is based on a very personal one-to-one relationship. Therefore, members are keen to know who wins the trust of powerful people in the bank". If a bank member decides to join another group, he can inflict a feeling of betrayal on others. Changing one's field is only acceptable through job rotation. The reason for this strong emotional bond is that Michiko creates a 'big family' atmosphere or 'paternalistic adhocracy' for its core employees, so that the bank is more than just a place for earning salaries. In other words, employment at Michiko "[is] not necessarily a contractual affair involving the performance of particular work or services, but [becomes] a kinship rite inducting a new member into the enterprise family to share in the work to be done" (Gregory, 1982:38).

\section{Conclusion}

This study reveals the extent to which knowledge sharing is supported by a large commercial bank in Japan. The wider institutional context in Japan, in which HRM practices, long-term employment relations, and personal social networks are embedded, create a framework for knowledge sharing different from that found in the West. The case of Michiko demonstrates that job security and commitment through life-time employment 
and formalised job rotation enable core employees to share experiences that constitute tacit knowledge, and elicit an enthusiasm and willingness to exchange information. Hence, life-time employment and the accompanying HRM practices that support welfare pension are also found to be influential in the sharing of knowledge.

The formation of personal social networks based on goodwill trust is also conducive to knowledge sharing. In-house training and job rotation act as catalysts in the building up of this trust. They serve as arenas in which core employees can engage in face-to-face communication and build up close personal relations. Hence, knowledge, as the community model (Swan, 1999) suggests, is shared through processes of social interaction in which social networking, social inclusion (and exclusion from the perspective of the specialists), and trust are of paramount importance. Technology, given the strict insistence by the Japanese State that banks should adopt the same infrastructure, is less significant in encouraging knowledge sharing across different social groups at Michiko.

Effective internal social networks in the bank contribute to the sharing of knowledge at several levels. These include individual-departmental, official-unofficial, and job-relatedpersonal networks. Fluid job descriptions create dependency relations and strengthen the internal social networks, which then serve as a medium for rapid information flow. For example, as each employee is a member of the same internal social network, he can receive information regarding the financial difficulty of a customer or the state-granted permission to launch a new product in a matter of a few days. Job-related information associated, for example, with a branch manager's rotation, the rate of pay-rise, and change in board membership can be disseminated in a day. At Michiko Bank, informal social networks are sustained by constantly tracing information to the point at which it is held and transferred to others in the network.

Although the notions of internal knowledge and information sharing are widely accepted and practised at Michiko, the external sharing of knowledge is highly discouraged among the generalists. This relates not only to the bank's business relationship with outside suppliers and customers, but also to the transfer of information to, and sharing of knowledge with, the branches. Michiko regards the most valuable source of information 
as that held in its internal social network. It does not see the need to gather information from external sources. As the banks perceive themselves as the primary producers and integrators of costly information of borrowers, "that is not available to the stock market" (Gerlach, 1992:12), they do not feel the need to consult external sources of information.

Perhaps a more convincing reason for low inter-firm knowledge sharing is that Michiko, like other Japanese financial institutions, is under regulatory surveillance to maintain confidentiality. In other words, state control minimises inter-bank co-operation. This poses a challenge to Michiko, as well as other Japanese banks, because of the need to adjust to current social and economic changes. The process by which Michiko and other similar banks can effectively initiate such adjustment merits further research.

\section{Future Implications}

Japan's financial market and the external factors surrounding the banks in Japan are changing. The Ministry of Finance is not as strong as it used to be, and financial products and banking business activities are gradually being diversified. This involves a shift away from traditional, centralised bureaucracies to greater inter-firm collaborations, due to the challenges presented by technological innovation and societal changes at the domestic and international levels. However, this change is not strongly felt among the financial institutions in Japan, for the threat of external competition has only recently been perceived as a problem. In the light of the ever-increasing competition, Japanese banks need to consider the external sources of information, in addition to the internal sources. According to Odagiri and Goto (1996:103), “competition and rapid changes in industrial structure play vital roles as [such] a threat". The authors argue that such a threat is seen as essential for organisations in achieving their potential efficiency.

Although it is difficult to initiate change in institutions that have grown strong roots in particular cultures and social processes, failure to transform can result in stagnation and high opportunity costs. In this quest to redesign Japanese financial institutions, both social factors and the hardware domain need to be taken into account (Scarbrough and Corbett, 1992). This paper has sought to illustrate the role of social processes and HRM practices in the sharing of knowledge within a Japanese bank, and to highlight the significance of low interaction with outside institutions. The case study findings indicate 
that Michiko operates along the lines of both traditional bureaucratic people management, as observed in its formal authority relations, and adhocracy, as seen in its emphasis on knowledge sharing through collaborative task sharing, trust building and personal social networking.

There is a growing concern that the low level of inter-bank co-operation in Japan does not allow for a quick response to environmental changes (e.g. Horiuchi, 1998). For the first time, after five decades of weak competition in the domestic market, Japanese banks are faced with having to compete with foreign financial institutions. This has raised fundamental questions in Japanese banks about the knowledge creation and innovation processes, especially with the growth of internet banking and electronic commerce.

\section{References}

Alvesson, M. (1993). "Organisations as Rhetoric: Knowledge Intensive Firms and the Struggle with Ambiguity”, Journal of Management Studies, 30 (6), pp. 997-1015.

Aoki, M. and H. Patrick (1994). The Japanese Main Bank System: Its Relevance for Developing and Transforming Economies. Oxford University Press, New York.

Appleyard, M. (1996). "How Does Knowledge Flow? Inter-firm Patterns in the Semiconductor Industry”, Strategic Management Journal, 17 (Winter Special Issue), pp. 137-154.

Besser, T. L. (1996). Team Toyota: Transplanting the Toyota Culture to the Camry Plant in Kentucky. State University of New York, New York.

DiMaggio, P. (1994). "Culture and Economy". In N. Smelser and R. Sedberg (eds.), The Handbook of Economic Sociology, pp. 27-50, Princeton University Press, Princeton, New Jersey.

Drucker, P. (1993). Post-capitalist Society. Butterworth Heinemann, New York.

Enkyo, S. (1993). Kinyu Jiyuuka Nyuumon (The Basis of Financial Liberalisation). Nihon Keizai Shinbunsha, Tokyo.

Finerty, L. (1997). "Information Retrieval for Intranets: The Case for Knowledge Management", Document World, 2 (5), pp.32-34.

Fontana, A. and J. H. Frey (1998). "Interviewing: The Art of Science”. In N. K. Denzin and Y. S. Lincoln (eds.), Collecting and Interpreting Qualitative Materials, Sage Publications, Thousand Oaks, California, pp. 47-78. 
Fruin, W. M. (1997). Knowledge Works: Managing Intellectual Capital at Toshiba. Oxford University Press, Oxford.

Garvin, D. (1993). "Building A Learning Organisation", Harvard Business Review, July/August, 71(4), pp. 78-91.

Gerlach, M. (1992). Alliance Capitalism. University of California Press, California. Glaser, B. G., and A. Strauss. (1967). The Discovery of Grounded Theory of Structure. Aldine Publishing Co, Chicago, Illinois.

Grant, R. M. (1996). "Toward a Knowledge-Based Theory of the Firm", Strategic Management Journal, 17 (Winter Special Issue), pp. 109-122.

Gregory, G. (1982). The Logic of Japanese Enterprise. Institute of Comparative Culture Business Series, Bulletin No. 92, Sophia University, Tokyo.

Hammersley, M. and S. Atkinson (1995). Ethnography: Principles in Practice, $2^{\text {nd }}$ edition. Routledge, London.

Hodgetts, R. and F. Luthans (1997). International Management, $3^{\text {rd }}$ edition, McGrawHill, New York.

Horiuchi, A. (1998). Kinyu System no Mirai (The Future of the Financial System). Iwanami Shinsyo, Tokyo.

Inkpen, A. and A. Dinur (1998). "Knowledge Management Processes and International Joint Ventures", Organisation Science, 9 (4), pp. 454-468.

Ito, O. (1995). Nihongata Kinyu no Rekishiteki Kozo (The Historical Structure of Japan's Financial System). University of Tokyo Press, Tokyo.

Iwata, R. (1982). Japanese Style Management: Its Foundation and Prospects. Asian Productivity Organisation, Tokyo.

Kazusaka, T. (1998). Nihongata Kinyu system no Tenki (The Turning Point for the Japanese Financial System). University of Tokyo Press, Tokyo.

Lane, C. (1997). "The Governance of Interfirm Relations in Britain and Germany: Societal or Dominance Effects?". In R. Whitley and P. H. Kristensen (eds.). Governance at Work, pp. 62-85, Oxford University Press, Oxford.

Leonard-Barton, D. (1992). "The Factory as a Learning Laboratory", Sloan Management Review (Fall), pp. 23-38.

Lincoln, Y., and E. Guba. (1985). Naturalistic Inquiry. Beveley Hills, California.

Mintzberg, H. (1973). The Nature of Managerial Work. Harper and Row, New York. 
Morgan, G. and A. Sturdy (2000). Beyond Organisational Change: Institutions, Discourses, and Identities in the UK Financial Services Industry. Macmillan Press, London.

Mowery, D., Oxley, J. and B. Silverman (1996). "Strategic Alliances and Inter-firm Knowledge Transfer", Strategic Management Journal, 17 (Winter Special Issue), pp. 77-91.

Nakamura, T. (1995). The Postwar Japanese Economy, $2^{\text {nd }}$ edition, University of Tokyo Press, Tokyo.

Nakane, C. (1970). Tate-shakai no Ningen-kankei (The Human Relationship within the Vertical Society), Kodansya, Tokyo.

Neuman, W. L. (1991). Social Researcher Methods: Qualitative and Quantitative Approaches. Allen and Bacon, Boston.

Nonaka, I. And H. Takeuchi (1995). The Knowledge-creating Company: How Japanese Companies Create the Dynamics of Innovation. Oxford University Press, New York.

Odagiri, H. and A. Goto (1996). Technology and Industrial Development in Japan, Clarendon Press, Oxford.

Orlikowski, W. J., G. Walsham, M. Jones, and J. DeGross (eds.) (1996). Information Technology and Changes in Organisational Work. Chapman and Hall, London.

Pan, S. L. (1999). “Knowledge Management at Buckman Laboratories”. In H. Scarbrough and J. Swan (eds.), Case Studies in Knowledge Management, pp. 76-84, Institute of Personnel and Development, London.

Richter, F-J. and K. Vettel (1995). "Successful Joint Ventures in Japan: Transferring Knowledge through Organisational Learning”, Long Range Planning, 28 (3), pp. 37-45.

Sako, M. (1992). Prices, Quality and Trust: Inter-firm Relations in Britain and Japan. Cambridge University Press, Cambridge.

Sasaki, N. (1990). Management and Industrial Structure in Japan, $2^{\text {nd }}$ edition, Pergamon Press, Oxford.

Scarbrough, H. and J. M. Corbett (1992). Technology and Organisation, Routledge, London.

Scarbrough, H. and J. Swan (1999). Case Studies in Knowledge Management, Institute of Personnel and Development, London. 
Shimizu, Y. (1999). "Incentive System no Sekkei" (Designing the Incentive System). In Research Group of Capital Markets (ed.), Shoken Keiei no Frontier (The Frontier of the Stock-broking Management), Seibunsha, Tokyo, pp. 193-236.

Starbuck, W. (1992). "Learning by Knowledge-Intensive Firms", Journal of Management Studies, 29 (6), pp. 713-740.

Swan, J. (1999). "Introduction". In H. Scarbrough and J. Swan (eds.), Case Studies in Knowledge Management. Institute of Personnel and Development, London, pp. 1-12. Teranishi, J. (1982). Nihon no Keizaihatten to Kinyu (Japanese Economic Development and Finance). Iwanami Shoten, Tokyo.

Tunzelmann, G. von (1995). Technology and Industrial Progress. Edward Elgar, Aldershot.

Whitley, R. (1997). "The Social Regulation of Work Systems". In R. Whitley and P.H. Kristensen (eds.), Governance at Work. Oxford University Press, Oxford, pp. 227-260.

Yoshida, K. (1996). Nihongata Keiei System (The Japanese Management System). Toyo Keizai Shimposya, Tokyo.

Zysman, J. (1994). "How Institutions Create Historically Rooted Trajectories of Growth", Industrial and Corporate Change, 3 (3), pp. 243-283. 